\title{
Hypothyroidism in one of monozygotic twins
}

\author{
M. W. MONCRIEFF \\ M.A., B.M., M.R.C.P. \\ Lecturer
}
R. G. MCARTHUR
M.D.(Alberta)
Research Fellow

Department of Paediatrics, University of Birmingham

Congenital abnormalities in monozygotic twins are common (Fogel, Nitowsky \& Gruenwald, 1965). However, hypothyroidism in only one of monozygotic twins is rare and a review of the literature revealed only the following cases.

Manson (1910) and Herman (1914) each reported an example of hypothyroidism in one of twin brothers but did not state whether the twins were monozygotic or not. Faxen (1935) reported two examples of hypothyroidism in one each of two pairs of twins and although in each case there was only one placenta, he did not believe that the twins could be identical as it seemed so improbable that only one of monozygotic twins could develop hypothyroidism. Hosen (1940) reported a 9-year-old child, one of monozygotic twins, with hypothyroidism who showed physical and mental retardation and stressed the importance of endocrinological studies when one of identical twins showed physical or mental deviation from the normal twin. Grebe (1952) briefly described the marked retardation in growth of a hypothyroid monozygotic twin and Lamy (1952) mentioned two further examples. Von Harnack (1953) and Von Harnack et al., (1958) described a monozygotic twin who was treated at the age of $7 \frac{1}{2}$ years with transplantation of thyroid tissue from the normal twin. The mother had developed thyrotoxicosis during pregnancy but did not receive any treatment for this until after delivery. Following the thyroid transplantation, the hypothyroid twin required smaller doses of thyroid than before the operation. Further cases of hypothyroidism in one of monozygotic twins were reported by Forsyth (1954), Warkany \& Selkirk (1955) and Pickering \& Koulischer (1956), The mother of the twins described by Warkany \& Selkirk suffered from hypothyroidism but received 3 grains $(200 \mathrm{mg})$ dried thyroid throughout pregnancy. Najjar \& Nassif (1963) described a monozygotic twin who developed congestive heart failure and lobar pneumonia which responded poorly to digitalization and antibiotics. The features of cretinism developed and rapid improvement following thyroid therapy was seen.

We report a further example of hypothyroidism in one of monozygotic twins.

\section{Case report}

J.H., the second of identical twins (Fig. 1), was born by breech delivery at 37 weeks' gestation, after surgical induction of labour for pre-

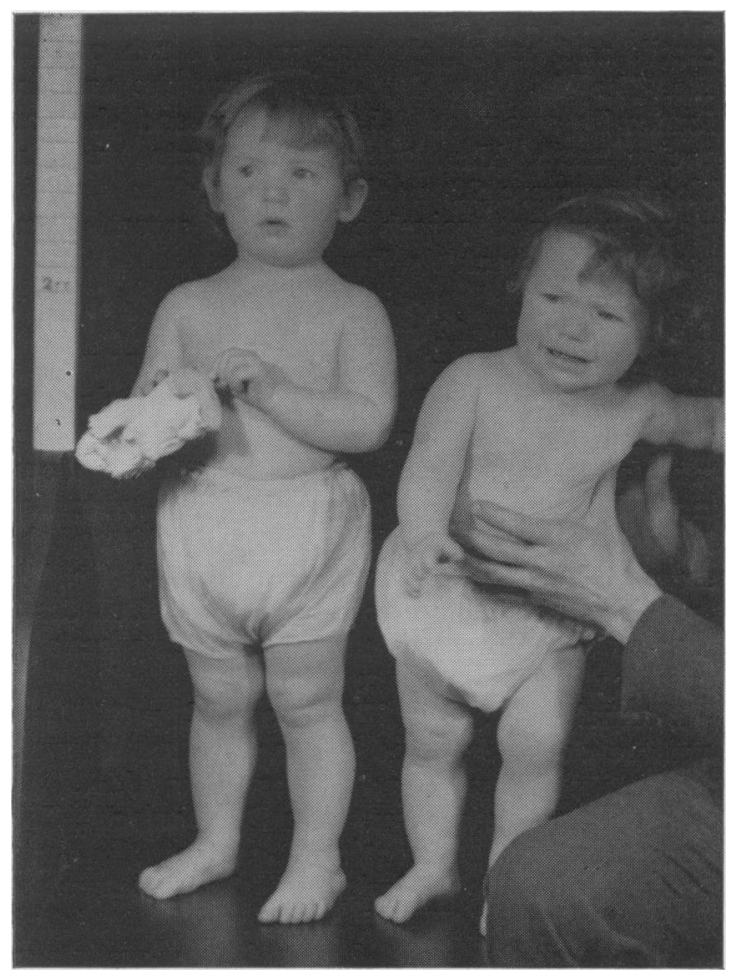

FIG. 1. 
eclamptic toxaemia. The placenta was monochorionic with an artery-to-artery and vein-to-vein anastomosis which showed that the twins were monozygotic. In neither case was there difficulty in delivery or in establishing respiration. J.H. was slow in development compared with her twin (Table 1).

TABLE 1

Growth and development

\begin{tabular}{lcc}
\hline & Normal twin & J.H. \\
\hline Birth weight & $6 \mathrm{lb} 2 \mathrm{oz}$ & $5 \mathrm{lb} 8 \mathrm{oz}$ \\
Sat up & 5 months & 10 months \\
Walked & 11 months & 2 years \\
Talked & 1 year & 19 months \\
First tooth & 5 months & 12 months \\
Height at & $33 \frac{1}{2}$ in. & 30 in. \\
22 months & (50th percentile) & (3rd percentile) \\
Weight at & $26 \frac{1}{2}$ lb & $22 \frac{1}{2}$ lb \\
22 months & (50th percentile) & (10th percentile) \\
I.Q. (Merrill & 104 & 66 \\
Palmer) & & (at 3 years after \\
& & treatment for 1 year) \\
\hline
\end{tabular}

She was first seen at the age of 22 months as part of a twin-survey. She had a poor appetite and was constipated and lethargic and had a croaky cry. Her height was below the third percentile and her weight was on the tenth percentile. The skin was dry and sallow, the anterior fontanelle measured $1.5 \mathrm{~cm}$ across and she had twelve teeth. The pulse was $80 / \mathrm{min}$ and the blood pressure $90 \mathrm{mmHg}$ systolic. The thyroid gland was not palpable and the second component of the ankle reflex was delayed.

\section{Investigations at 22 months of age}

The serum protein bound iodine (SPBI) was $1 \cdot 3,2 \cdot 0,1 \cdot 1 \mu \mathrm{g} / 100 \mathrm{ml}$. The serum cholesterol was 272 and $274 \mathrm{mg} / 100 \mathrm{ml}$ and the ${ }^{132} \mathrm{I}$ uptake, neck-thigh ratio at $2 \mathrm{hr}$, was $2 \cdot 3$. Following TSH stimulation (1 unit daily was given for 3 days) the SPBI was 1.6 and $1.3 \mu \mathrm{g} / 100 \mathrm{ml}$ the serum cholesterol $298 \mathrm{mg} / 100 \mathrm{ml}$ and the ${ }^{132} \mathrm{I}$ uptake, neck-thigh ratio at $2 \mathrm{hr}$, was 2.5 . Scanning of the neck revealed no convincing peak of counting rate at any one point.

Normal twin: the SPBI was $8.2 \mu \mathrm{g} / 100 \mathrm{ml}$ and the cholesterol was $169 \mathrm{mg} / 100 \mathrm{ml}$. Thyroid autoantibodies were not detected in J.H., her twin, or in either parent (Dr D. Doniach). The bone age was 3 months. X-ray of the knee showed slight irregularity of the structure of both epiphyses (Fig. 2). X-ray of the skull showed that the area of lateral cross-section of the pituitary fossa was $66 \mathrm{~mm}^{2}$, which is at the ninety-fifth percentile for a 2-year-old girl; the sellar index was $2 \cdot 4$, which is in the upper normal range.

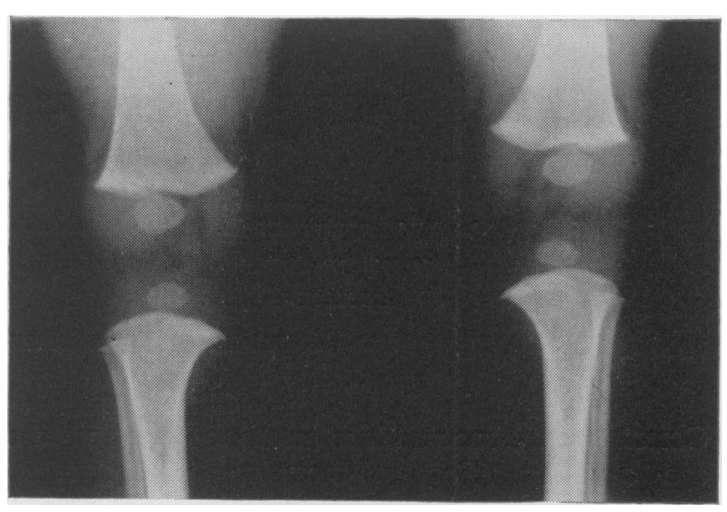

FIG. 2.

\section{Discussion}

The investigations in this child confirmed the clinical diagnosis of hypothyroidism but the cause is unknown. Genetic factors cannot be manifest in only one of monozygotic twins. Autoimmune disease has been shown to cause some cases of hypothyroidism (Blizzard et al 1960) but thyroid autoantibodies were not de tected in J.H. or in her family. Some children with hypothyroidism have been found to have maldescent of the thyroid gland (Andersen, 1960), but scanning of the neck after administration of ${ }^{132} I$ failed to reveal an ectopic site of thyroid activity. Hypothyroidism may be secondary to failure of TSH secretion and although administration of TSH in this case failed to cause an increase in the SPBI and in the ${ }^{132}$ I uptake, this may have been due to atrophy of the thyroid gland due to lack of endogenous TSH after birth. The dose of TSH may have been inadequate as 10 units daily have been recommended (Wilkins, 1965). As the twins were born 3 weeks prematurely, the irregularity of the epiphyses at the knee is not evidence that the disease began before birth. It is possible that the hypothyroidism in this case is due to failure of TSH secretion, perhaps due to hypothalamic damage at birth. However, the size of the pituitary fossa in J.H. was at the upper limit of normal as shown by the sellar index (Riach, 1966). It has been shown that the pituitary fossa is usually increased in size in hypothyroidism in childhood (Bellini \& Neves, 1956). The excretion of TSH has been found to be raised in cretinism (Gilliland \& Strudwick, 1956). In mice destruction of the thyroid gland gives rise to TSH- 
secreting tumours of the pituitary gland (Furth et al., 1955). In this case the secretion of TSH may have been increased and the hypothyroidism due to maldevelopment of the thyroid gland in utero. Severe brain damage may have been prevented by thyroid hormone passing from the normal twin to J.H. through the placental anastomosis before birth.

In only four of the cases mentioned was evidence produced to prove monozygocity and none of those included examination of the placenta. In Von Harnack's case monozygosity was assumed on the basis of finding that the blood groups and certain physical characteristics were identical in both twins. Symptoms in the hypothyroid twin began during the 2nd month of life. Treatment with thyroid extract was started at $2 \frac{1}{4}$ years of age and at $4 \frac{3}{4}$ years the affected twin had an I.Q. of 80 compared with the normal twin's 110. Homotransplantation of thyroid tissue was performed at $7 \frac{1}{2}$ years and following this the abnormal twin had an I.Q. of 100 compared with the normal twin's 120 . The case reported by Forsyth was also considered to be a monozygotic twin on the basis of identical blood groups and various physical characteristics. This infant was a slow feeder and was given thyroid extract for the first 3 weeks of life. Although the infant continued to have typical symptoms, treatment was not restarted until the age of $2 \frac{1}{2}$ years. At $4 \frac{1}{2}$ years the abnormal twin's I.Q. was 66 and the normal twin's was 109. The twins reported by Warkany \& Selkirk were also thought to be monozygotic as they had identical blood groups and features. Symptoms began in the hypothyroid twin at 3 months of age and treatment was started at this time but only from 6 to $15 \mathrm{mg}$ of thyroid daily were given and treatment was irregular from 1 year onwards. Regular treatment with adequate amounts of thyroid was given from 4 years and at 4 years 8 months of age the hypothyroid twin had an I.Q. of 86 while her twin's was 138. Pickering \& Koulischer's case was also thought to be monozygotic because the twins had identical blood groups. Symptoms had developed by 6 weeks and treatment was started at this time. The I.Q. at 4 years was 80 and the I.Q. of the normal twin was 91 .

All four of these patients had developed symptoms of hypothyroidism by 3 months of age and our own patient had an equally early onset, as shown by the irregularity of the epiphyses at the knee. This early onset would suggest a severe degree of hypothyroidism. In the series reported by Smith, Blizzard \& Wilkins (1957), of twentytwo cases of severe cretinism where treatment was started after the first year of life, $40 \%$ had an I.Q. of less than 50. As treatment in three of the twins was not started until approximately 2 years of age and was inadequate in the fourth, the subsequent mental development would be expected to be very poor. However, two children had an I.Q. of 66 and two of 80 or over. The prognosis for mental development in one of monozygotic twins with hypothyroidism may be better than for a singleton with a similar degree of thyroid dysfunction. This could be due to the prevention of severe brain damage in utero by thyroid hormone passing from the normal twin to the abnormal twin through a placental vascular anastomosis which is known to occur in $85 \%$ of monochorionic twins (Benirschke \& Driscoll, 1967).

\section{Acknowledgments}

We thank Dr R. Astley, Dr H. Cameron, Dr D. Doniach and Dr G. Newsholme for performing special investigations, Miss H. Newton for assessing the I.Q., Dr M. Griffiths for advice and Professor D. V. Hubble for his help.

\section{References}

ANDERSEN, H.J. (1960) Studies of hypothyroidism in children. Acta paediat. (Uppsala), Suppl. 50, 125.

Bellini, M.A. \& NeVes, I. (1956) The skull in childhood myxedema, its roentgen appearance. Amer. J. Roentgenol. $76,495$.

BENIRSCHKe, K. \& DRISColl, S.G. (1967) The Pathology of the Human Placenta. Springer, Heidelberg.

Blizzard, R.M., Chandler, R.W., Landing, B.H., Pettit, M.D. \& WEST, C.D. (1960) Maternal autoimmunisation to thyroid as a probable cause of athyrotic cretinism. New Engl. J. Med. 263, 327.

FAXEN, N. (1935) Hypothyroidism in one of twins. Acta paediat. (Uppsala), 17, 565.

Fogel, B.J., Nitowsky, H.M. \& Gruenwald, P. (1965) Discordant abnormalities in monozygotic twins. J. Pediat. $66,64$.

FoRsYTH, C.C. (1954) Cretinism in one of monozygotic twins. Gt Ormond St. J. 7, 62.

FuRTH, J., DENT, J.N., BuRnetT, W.T. \& GADSDEN, E.L. (1955) The mechanism of induction and the characteristics of pituitary tumours induced by thyroidectomy. J. clin. Endocr. 15, 81.

Gilliland, I.C. \& STRudwick, J.I. (1956) Clinical application of an assay of thyroid-stimulating hormone in relation to exophthalmos. Brit. med. J. i, 378.

GrEBE, H. (1952) Diskordanzursachen bei erbgleichen Zwillingen. Acta Genet. med. (Roma), 1, 89.

Herman, C. (1914) Sporadic cretinism-A clinical study of 41 cases. N.Y. J. Med. 14, 394.

Hosen, H. (1940) Thyroid deficiency in twins. J. Pediat. 16, 210.

Lamy, M. (1952) Précis de Génétique Médicale. Doin, Paris.

Manson, L.S. (1910) Unusual manifestation in cretinism. Med. Rec. 77, 7.

NAJJAR, S.S. \& NASSIF, S.I. (1963) Congestive heart failure in infancy due to hypothyroidism. Acta paediat. (Uppsala), 52, 319.

Pickering, D.E. \& Koulischer, N. (1956) Discordance of cretinism in monozygotic twins. Amer.J. Dis. Child. 92, 63. 
RIACH, I.C.F. (1966) The Stella Index-A relationship between the area of the sella turcica and the lateral area of the skull. Brit. J. Radiol. 39, 824.

Smith, D.W., Blizzard, R.M. \& Wilkins, L. (1957) The mental prognosis in hypothyroidism of infancy and childhood. Pediatrics, 19, 1011.

Von HaRnack, G.A. (1953) Eineiige Zwillinge mit diskordanter Hypothyreose. Arch. Kinderheilk, 146, 60.
Von Harnack, G.A., Horst, W., Lenz, W. \& ZukschWERDT, L. (1958) Homotransplantation of thyroid tissue in uniovular twins. Germ. med. Mth. 3, 172.

Warkany, J. \& SelkIRK, J. (1955) Discordant monozygotic twins. Amer. J. Dis. Child. 89, 144.

WILKINs, L. (1965) The Diagnosis and Treatment of Endocrine Disorders in Childhood and Adolescence, 3rd edn. Thomas, Springfield, Illinois.

\title{
IATS activity, exophthalmos and digital clubbing associated with myxoedema
}

\author{
Peter Beighton \\ M.R.C.P., M.R.C.P.(Ed.), D.T.M. \& H. \\ Formerly Medical Registrar, Hillingdon Hospital; \\ Now Medical Registrar, St Thomas' Hospital
}

THE ASSOciation of exophthalmos and finger clubbing with thyrotoxicosis is well known (Malkinson, 1963). It has been postulated that the long acting thyroid stimulator (LATS) might be the common aetiological factor.

The case described is that of a patient with proven myxoedema, who had never had any previous episodes of hyperthyroidism, who exhibited exophthalmos and digital clubbing, and in whom the serum LATS level was raised. In addition she had rheumatoid arthritis and pernicious anaemia. The significance of these associations is discussed.

\section{Case report}

The patient, a 67-year-old spinster, was admitted to Hillingdon Hospital in June 1966. In 1944 she had experienced gradual 'slowing down' together with changes in her skin and hair. Myxoedema was diagnosed clinically and treatment with thyroxine had continued from that time until 4 months before when she had neglected to take her tablets. In 1964 proptosis developed and has progressed. Tarsorrhaphy was performed in 1965 for a left-sided corneal ulcer. She developed joint symptoms in 1960 which led to a a diagnosis of rheumatoid arthritis. At this time she had an ESR of $50 \mathrm{~mm} / \mathrm{hr}$ and a negative test for the rheumatoid factor. By 1966 she was unable to walk and surgical arthrodesis of the left knee joint was later carried out.

Pernicious anaemia was diagnosed in 1966 during routine investigation of a symptomless anaemia. In 1930 she had rheumatic fever but there were no apparent sequelae. She had never had a goitre.
There was no family history of thyroid disorder, arthritis or pernicious anaemia.

Examination. The patient was a middle-aged lady with sparse, coarse hair, a dry thickened skin and the facial appearance characteristic of myxoedema (Fig. 1). Her height was $5 \mathrm{ft} 2$ in. (152.5

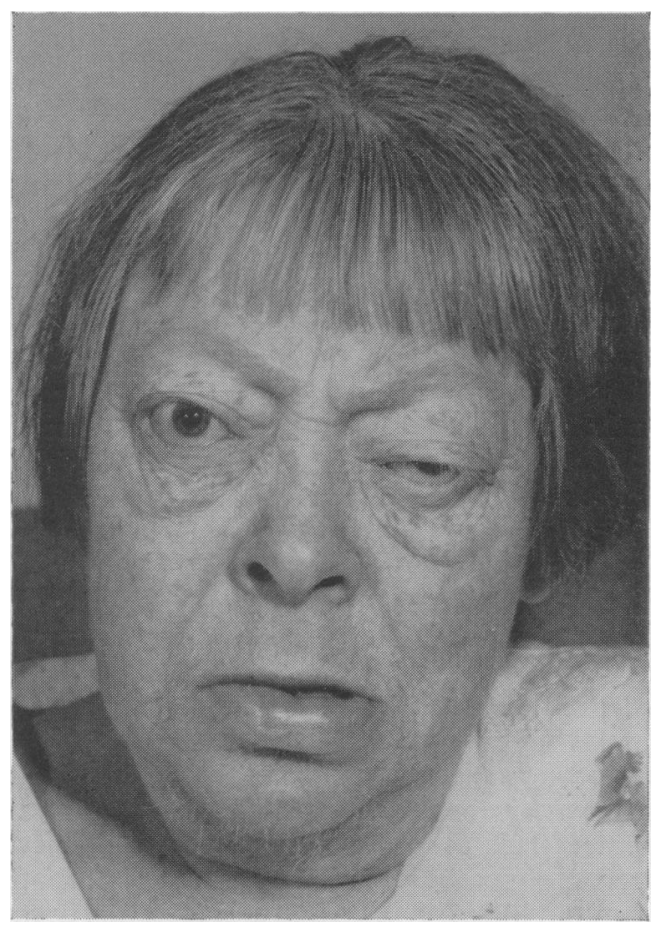

Fig. 1. 